\title{
Co-composting Peat and Kitchen Wastes for the Production of Soil-Compost
}

\author{
Chee-Ming Chan ${ }^{1}$, Mastura Selamat ${ }^{1}$, Mohammad Zawawi Rosman ${ }^{1}$ and Angzzas Sari Mohd Kassim ${ }^{1}$ \\ ${ }^{1}$ Faculty of Engineering Technology, Universiti Tun Hussein Onn Malaysia, Pagoh 84600, Malaysia., \\ chan@uthm.edu.my
}

\begin{abstract}
Due to its unsuitability for construction and agriculture, peat has been long considered as the worst soil compared to the other soil types. Peat is formed from dead plant waste at various stages of decay. The high organic and carbon content combined with high levels of acidity and moisture content make peat favourable only for certain crops. However, the unique constituents and characteristics of peat can be used to advantage with careful strategic planning. In the present study, peat was used as a medium for composting plant-based kitchen wastes, where the peat was intended as a source of brown matter in the degradation process. The selection of plant-based kitchen wastes included green cabbage, Chinese white cabbage and banana peels, which served as the nitrogen material in composting. Anaerobic and aerobic com-posting procedures were implemented for comparison of the peat-kitchen wastes biodegradation effectiveness. The key parameters moni-tored were moisture content, temperature, $\mathrm{pH}$ and $\mathrm{C}: \mathrm{N}$ ratio. Left to compost for up to 6 weeks, it was found that aerobic composting pro-duced better results, though $\mathrm{C}: \mathrm{N}$ monitoring suggested the need to optimize that with moisture level in the compost to avoid long treatment time or to counter low decomposition efficiency.
\end{abstract}

Key words: Aerobic, Anaerobic, Compost, Kitchen Waste, Peat.

\section{INTRODUCTION}

Malaysia has the largest wetland (peat swamp forest) which cov-ered about $75 \%$ of the country's total. It is estimated that 1.54 mil-lion hectares of peat swamp forest is still remain. Approximately $70 \%$ of peat swamp forest is located in Sarawak, less than $20 \%$ in Peninsular Malaysia and the remaining 10\% in Sabah [1]. Peat soil in Malaysia, especially Johor, has the fourth largest distribution in Malaysia after Sarawak with an area of 13,000 hectares of peat land. Most wetland in western Johor is located in Pontian, Batu Pahat and Muar, while in the eastern part of Johor, there are some in the district of Mersing. While the soil is unfavourable for construction, its nutrient-rich nature may make it a suitable medium for compost.
The disposal of food waste is a growing problem worldwide: Japan recorded about 17 million metric tonnes of edible food disposal annually [2], India had 30\% of fruit and vegetable produces dis-posed of due to poor cold storage facilities [3] and China is experiencing a staggering rise in household waste up to $70 \%$ [4]. In Malaysia, more than a decade ago, an average of $800 \mathrm{~g}$ of waste is disposed by each individual within a day in Malaysia [5]. This means that in one day the garbage produced by all 28 million people can produce at least 30,000 tonnes per day, equivalent to $10,950,000$ tonnes of waste a year. Fast forward to 5 years ago, the amount of waste produced by Malaysians could cover the entire state of Perlis $\left(\right.$ area $821 \mathrm{~km}^{2}$ ) within 5 days if it was collected and flattened [22]. In addition, food wastes are detrimental to the environment via greenhouse gas emissions, both from embedded emissions in the food production, processing, transportation and retailing, as well as decomposition of the organic substances once disposed of in landfills [6]. In short, kitchen and food wastes which constituted most of the household waste is a pressing issue requiring urgent attention and actions.

An economical yet effective method is to compost these materials for reuse as fertilizers. Composting is the decomposition and stabilization of materials biological organic under controlled conditions for the end product that is beneficial to the soil [7]. Decomposition and stabilization of the organic compounds occur under thermophilic conditions with biologically produced heat [23]. Moreover, compositing is established as an effective way to treat green and food wastes, e.g. [8]. By products of the composting process can be easily disposed of in landfill sites without negatively affecting the environment. Composting effectively creates a more humid, soil conditioner-quality organic matter applicable as organic fertilizer for agricultural land as it is more easily assimilated to plants [9]. Basically the process is environmental-friendly, clean and typically low-toxic. It is an alternative to conserve or re-use resources to produce something useful, such as fertilizer for the agricultural industry, considering that the compost produced is expected to contain trace element such as nitrogen, phosphorus and potassium that is suitable for plant growth. Nonetheless due to safety concerns as well as competition from chemical 
Chee-Ming Chan et al., International Journal of Emerging Trends in Engineering Research, 8(1.2), 2020, 248- 252

fertilizers, the demand for fertilizers derived from composts are remain low [10]-[12].

The present study explored the potential of co-composting soil such as peat and plant-based kitchen waste such as vegetables and fruits as brown and green matter respectively. Much on the available literature on co-composting deals other types of soil medium such as loam, sandy-loam and clay [13],[14]. However, peat is high in nutrient as compared to the other type of soil, hence peat was used in the study as compost medium. The studied peat was obtained from Parit Nipah in Johor, Malaysia. A total of 6 composting chambers were set up for 6-week long experimental work, which included aerobic and anaerobic composting conditions. Measurements were taken regularly over the period on the moisture content, temperature, $\mathrm{pH}$ as well as $\mathrm{C}$ : $\mathrm{N}$ ratio.

\section{MATERIALS AND METHOD}

\subsection{Peat}

Peat is generally loose with high organic matter content [15]. It is also high in humic substances (humus and humic acids) that give a typically dark brown to black colour. Because of the colour, peat or brown matter known as a carbon. In other way compost is a break down organic waste into humus that can be reused as a beneficial nutrient rich resource of organic soil amendments.

Some key features of peat include $\mathrm{pH}$ ranging from 3.0-4.5, organic carbon content of 30-40\%, and water content from $200-2000 \%$. The high natural water holding capacity of peat is attributed to the soil structure characterized by organic coarse particles (fibers), which can hold a considerable amount of water since the soil fibers are very loose and hollow. Properties of the peat used in the study is presented in Table 1.

Table 1: Physical and chemical properties of peat

\begin{tabular}{|l|c|}
\hline Properties & Results \\
\hline $\mathrm{pH}$ & 4 \\
\hline $\mathrm{sg}\left(\mathrm{mg} / \mathrm{m}^{3}\right)$ & 1 \\
\hline Organic content $(\%)$ & 49.72 \\
\hline Moisture content $(\%)$ & 371 \\
\hline Temperature $\left({ }^{\circ} \mathrm{c}\right)$ & 24 \\
\hline $\begin{array}{l}\text { Ammonia nitrogen, } \mathrm{NH} 3-\mathrm{N} \\
(\%)\end{array}$ & 1.4 \\
\hline Phosporus, $\mathrm{P}(\%)$ & 0.76 \\
\hline Potassium, $\mathrm{K}(\%)$ & 5.15 \\
\hline Calcium, Ca $(\%)$ & 4.87 \\
\hline Magnesium, $\mathrm{Mg}(\%)$ & 0.59 \\
\hline Carbon, $\mathrm{C}(\%)$ & 0.1 \\
\hline
\end{tabular}

\subsection{Organic kitchen wastes}

The organic kitchen wastes such as produced by restaurants and canteens form a major component of purifying organic wastes. Kitchen waste is useful to compost because kitchen waste contains green matter such as vegetables and fruits that can be a source of nitrogen for the compost. The main problems encountered with kitchen waste composting are its high moisture content, need of bulking substrate and constituents unacceptable for worms [16]. Fresh banana peel, Chinese white cabbage and ordinary cabbage were used as kitchen waste samples in the study.

\subsection{Compost chamber}

Composting was conducted in a 15-litre plastic water dispenser, with the size of $290 \mathrm{~mm}$ long, $280 \mathrm{~mm}$ wide and $342 \mathrm{~mm}$ high such as in Figure 1. The raw materials were placed in a basket and raised from the base of the chamber to allow drainage and collection of the compost tea. The chamber was kept covered to avoid direct sunlight. Ventilation was provided by a number of $1.2 \mathrm{~cm}$ diameter holes on the cover for aerobic condition composting.
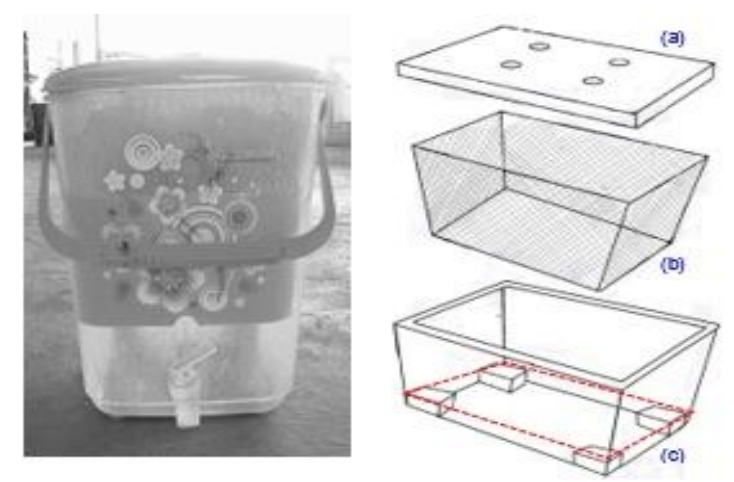

Figure 1: Composting chamber setup; (a) cover, (b) raised compost basket and (c) leachate collection trough

\subsection{Composting procedures}

Fresh banana peels, Chinese white cabbage and ordinary cabbage were withered under natural atmospheric condition for about 1 day, then chopped into small pieces of $<1 \mathrm{~cm}$ lengths. $250 \mathrm{~g}$ of the plant-based waste mixtures were then thoroughly mix with $6 \mathrm{~kg}$ of peat to obtain following formulations: peat + cabbage (PC), peat + Chinese white cabbage (PS) and peat + banana peel (PB). Suffix of A and B are used to represent aerobic and anaerobic conditions respectively, e.g. PCA refers to peat + cabbage in aerobic composting. A similar concept of study has been reported by Awasthi et al. [17], by which the organic matter is degrade into organic product known as compost. 
Chee-Ming Chan et al., International Journal of Emerging Trends in Engineering Research, 8(1.2), 2020, 248- 252

The peat-waste mixtures were placed in 6 compost chambers to simulate aerobic and anaerobic composting. The chambers were kept indoors at room temperature and away from direct sunlight for a period 6 weeks. In the aerobic setup, the compost was mixed manually every 2 days throughout the composting period. The samples were tested for moisture content, temperature, $\mathrm{pH}$ as well as $\mathrm{C}: \mathrm{N}$ ratio over the 6-week composting period.

\section{RESULTS AND DISCUSSION}

\subsection{Moisture Content}

The moisture content profiles for the different composting conditions are illustrated in Figure 2. The peat-waste mixtures had an initial water content of approximately $370 \%$ and all samples generally showed a slight rise in week 2 followed by continuous decline after that, regardless of the aeration conditions. However, the fluctuations were more significant for the aerobic chambers, where PBB underwent the highest moisture loss, i.e. $40 \%$ reduction. Clearly, with access to ventilation decomposition of the banana peels were well underway from beginning of the composting period. Variations in the moisture loss in the anaerobic chambers were less dramatic, suggesting lower rates of decomposition under oxygen-deprived conditions. Note that high moisture content could displace air from the voids between the particles causing anaerobic conditions, while a relatively dry composting condition deprives micro-organisms of the water needed for metabolism, resulting in sluggish decomposition of the organic matter.

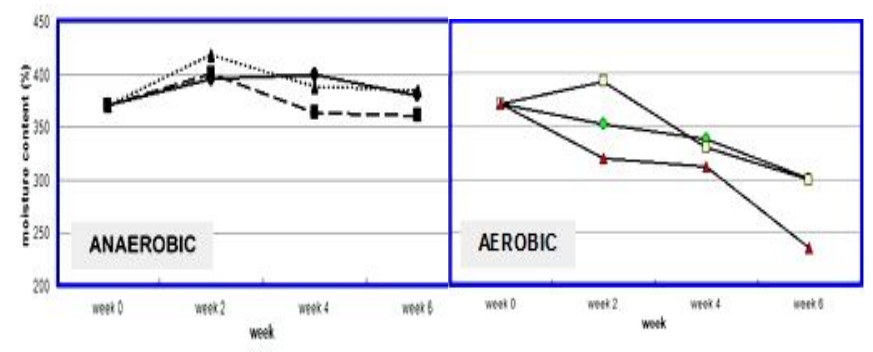

Figure 2: Moisture content changes with time

The suppressed oxygen transfer efficiency also contributed to lower microbial activity in the presence of high moisture level, accompanied by less remarkable rise in the temperature which further slowed down the moisture depletion process. Indeed, Liang, Das \& McClendon [18] reported constant temperature in aerobic composting at low moisture range, i.e. $57^{\circ} \mathrm{C}$ for $30-40 \%$ moisture content, indicating the importance of striking a balance between these key parameters in achieving high composting efficiency. Nonetheless Guo et al. [19] did not observe significant effect of moisture content on the stability and quality of compost, in comparison with the factors of aeration and $\mathrm{C}: \mathrm{N}$ ratio

\subsection{Temperature}

The temperature profiles for the compost samples are illustrated in Figure 3. The initial temperature was about $26-28{ }^{\circ} \mathrm{C}$ and constantly increased for both test conditions, though the aerobic samples showed relatively unchanged temperature within the first 2 weeks. This is indicative of a sluggish start to the peat-waste degradation process, probably attributed to ventilation aiding in heat dissipation at the early stage of composting.

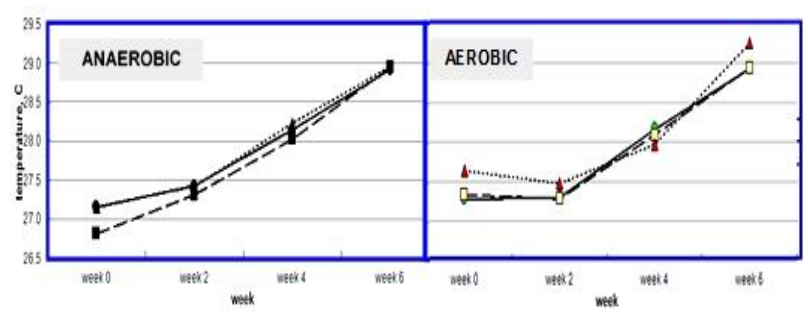

Figure 3: Temperature changes with time

Normally, the temperature of the compost is expected to rise in the first week (mesophilic stage) and reaches the maximum in 4 weeks (thermophilic stage) before stabilizing to the ambient temperature thereafter. As none of the plots reach a plateau, it was postulated that 6 weeks was not sufficiently long for the completion of the thermophilic composting stage. Nonetheless both composting conditions produced very similar temperature rise from week 2 onwards, i.e. approximately $0.38{ }^{\circ} \mathrm{C}$ per week, with a seeming continuous increment trend beyond 6 weeks. In addition, Koyama et al. [20] reported a shift in the dominant bacterial group of the compost with temperature change, resulting in possible rise of the composting rate.

\section{$3.3 \mathrm{pH}$}

Figure 4 summarizes the $\mathrm{pH}$ variation of the samples. All samples remained in the acidic $\mathrm{pH}$ range $(<4)$ within the 6-week composting period, and recorded similar decline in the first 2 weeks, a relative plateau between week 2 and 4 , followed by a gradual climb entering the second month of the composting period, likely due to ammonia volatilization and increase in the concentration of water-soluble base cations with organic matter decomposition. The generally low $\mathrm{pH}$ of the compost was due to admixing with peat, a naturally acidic highly organic soil.

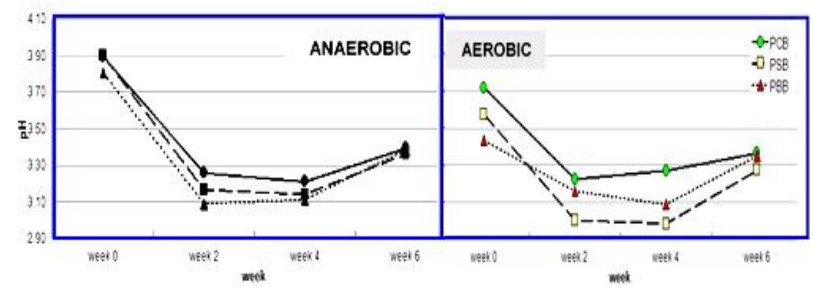

Figure 4: $\mathrm{pH}$ changes with time 
Chee-Ming Chan et al., International Journal of Emerging Trends in Engineering Research, 8(1.2), 2020, 248- 252

Anaerobic conditions appeared to have the same effect on the composting samples regardless of the mixtures, as shown by the close layout of the plots. Aerobic composting, on the other hand, caused more variations in the $\mathrm{pH}$ changes, where both PSB and PCB showed more significant fluctuations in $\mathrm{pH}$ compared to PBB. However, the $\mathrm{pH}$ values for all cases appeared to stabilize at about 3.4 and 3.3 for the anaerobic and aerobic conditions respectively after 6 weeks of composting. The subsequent rise in $\mathrm{pH}$ for all samples in week 4-6 (and seemingly beyond) could be attributed to the conversion of organic nitrogen to ammonium nitrogen [21].

\section{4 $\mathrm{C} / \mathrm{N}$ ratio}

Figure 5 shows the $\mathrm{C} / \mathrm{N}$ ratio in both anaerobic and aerobic composting conditions. It is interesting to note the rather varied C:N ratio trends recorded for each sample over the 6-week composting period. In the anaerobic chamber, PCB showed a dramatic rise in week 2 followed by an equally sharp after that before stabilizing to about 0.7 . The other 2 samples showed far less fluctuations in $\mathrm{C}: \mathrm{N}$ ratio over the 1.5 months, especially for PSB. Under aerobic conditions, PCB underwent a sharp decline in $\mathrm{C}: \mathrm{N}$ ratio before climbing consistently form week 2 onwards to reach 1.55. PSB demonstrated a decrease in $\mathrm{C}: \mathrm{N}$ ratio between week $2-4$, while remaining relatively unchanged between week $0-2$ and 4-6, recording a final reading of 0.60 .

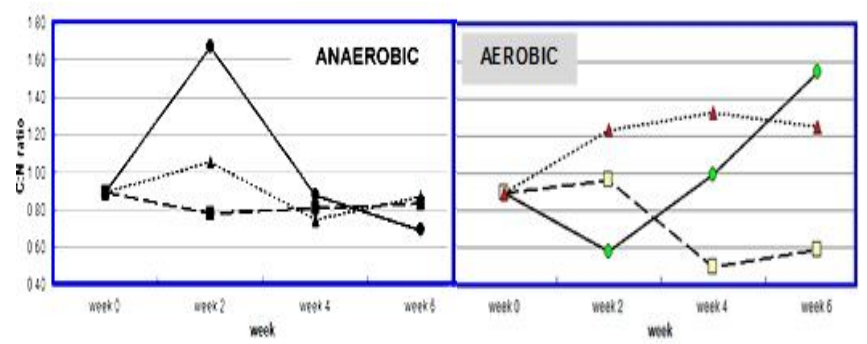

Figure 5: $\mathrm{C} / \mathrm{N}$ ratio changes with time

In comparison, $\mathrm{PBB}$ which showed rather constant $\mathrm{C}: \mathrm{N}$ readings throughout the 6 weeks in anaerobic condition demonstrated a nota-ble $\mathrm{C}: \mathrm{N}$ increase in the aerobic chamber for the first 2 weeks before levelling off after that. It is suggestive that ventilation had a marked effect on the decomposition processes and rates, though only PCB showed promising signs of attaining higher $\mathrm{C}: \mathrm{N}$ ratio. According to Darwaty [24], a matured compost would appear blackish in colour with a strong earthy smell and $\mathrm{C}: \mathrm{N}$ ratio in the range of 10-20:1. Apparently none of the samples in the current study reached the high $\mathrm{C}: \mathrm{N}$ ratio, suggesting unsuitable composting materials and/or inadequate composting period to reach maturity. Overall, increasing C:N ratio corresponded with decreasing moisture content, especially for samples PCB and PBB (Figures $2 \& 5$ ).

\section{CONCLUSIONS}

The peat-waste compost samples showed more dramatic moisture content changes in the aerobic condition with PBB undergoing the highest moisture loss, while temperature monitoring revealed the 6-week composting period to be inadequate for completion of the mesophilic stage, hence absence of the constant temperature attainment in all cases. $\mathrm{pH}$ was found to decrease initially and remained constant between week 2 and 4, before gradually climbing after that to reach a common acidity (3.3-3.4) for all cases. None of the compost samples reached $\mathrm{C}: \mathrm{N}$ ratios greater than 2, suggesting incompatible composting materials and/or inadequate composting period. Also, excessive moisture coupled with low C:N ratio would result in sluggish degradation process. Hence, it is recommended to use a suitable composting material and prolong the composting period in the future study. All in all, peat-kitchen waste showed potential for co-composting in an economical manner for small households especially where the quantity of disposed materials is comparatively low.

\section{ACKNOWLEDGEMENT}

The study was funded by research grant Tabung Penyelidikan RMC Vot E15501, UTHM.

\section{REFERENCES}

1. S. Funakawa, K. Yonebayashi, F. S. Jong and E. O. K. Chai. Nutritional environment of tropical peat soils in Sarawak, Ma-laysia based on soil solution composition. Soil Science \& Plant Nutrition, Vol. 42, No. 4, pp 833-843, 1995.

2. I. Morisaki. Pattern of Food Losses in Households: A Case Study in Oita Prefecture Japan (Published M. Sci. Thesis). Ritsumeikan Asia Pacific University, 2011.

3. B. Mukherji and B. Pattanayak. New Delhi starts drive to root out hunger. Retrieved January 8, 2019, from http://online.wsj.com/article/SB10001424052702, 2011.

4. X. Zheng, K. Wang and A. Cheng.. China Daily, 2019.

5. A. Sobian. Solid waste management and related problems. Institute of Islamic Understanding Malaysia (IKIM), 2003.

6. T. Garnett. FCRN report Cooking up a storm: Food, greenhouse gas emissions and our changing climate. International Journal of Climate Change Strategies and Management, Vol. 1, No. 2, pp 1-156, 2009.

7. E. Madejon, M. J. Diaz, R. Lopez and F. Cabrera. New approaches to establish optimum moisture content for compostable materials. Bioresources Technology, Vol. 85, No. 1, pp 73-78, 2002.

8. H. Nakasaki and A. Obtaki. A simple numerical model for predicting organic matter decomposition in a fed-batch composting operation. Journal of Environmental Quality, Vol. 31, No. 3, pp 997-1003, 2002. 
9. A. Segatelli, P. Andressa, P. Giovanni, S. Marcos and D. B. Tatiane. Quality of organic compost for vegetable planting. Proceedings of the 5th Ibero-American Congress on Entrepreneurship, Energy, Environment and Technology-CIEEMAT, Portalegre, Portugal, 2020.

10. M. A. Qazi, M. Akram, N. Ahmad, J. F. Artiola and M. Tuller. Economical and environmental implications of solid waste compost applications to agricultural fields in Punjab, Pakistan. Waste Management, Vol. 29, No. 9, pp 2437-2445, 2009.

11. I. Aye and E. R. Widijaya. Environmental and economic analysis of waste disposal op-tions for traditional markets in Indonesia. Waste Management, Vol. 26, No.10, pp 1180-1191, 2006.

12. G. Danso, P. Dreschel, S. Fialor and M. Giordano. Estimating the demand for municipal waste compost via farmer's willingness-to-pay in Ghana. Waste Management, Vol. 26, No. 26, pp 1400-1409, 2006.

13. S. M. Aggelides and P. A. Londra. Effect of compost produced from town wastes and sewage sludge on the physical properties of a loamy and a clay soil. Bioresource Technology, Vol. 71, No. 3, pp 235-259, 2000.

14. C.J. Schmid, J.A. Murphy and S. Murphy. Effect of tillage and compost amendment on turfgrass establishment on a compacted sandy loam. Journal of Soil and Water Conservation, Vol. 72, No. 1, pp 55-64, 2017.

15. B. K. Huat. Organic and Peat Soils Engineering. Malaysia: Universiti Putra Malaysia Press, 2004.

16. J. Nair, V. Sekiozoic \& M. Anda. Effect of Pre-composting on Vermicomposting of Kitchen Waste. Bioresourece Technology, Vol. 97, pp 2091-2095, 2006.

17. S. K. Awasthi, S. Sarsaiya, M. K. Awasthi, T. Liu, J. Zhao, S. Kumar and Z. Zhang. Changes in global trends in food waste composting: Research challenges and opportunities. Bioresources Technology, Vol. 299, 122555, 2020.

18. C. Liang, K. C. Das and R. W. McClendon. The influence of temperature and moisture content regimes on the aerobic microbial activity of a biosolids composting blend. Bioresources Technology, Vol. 86, No. 2, pp 131-137, 2003.

19. R. Guo, G. Li, T. Jiang, F. Schuchardt, T. Chen, Y. Zhao, and $Y$. Shen. Effect of aeration rate, $\mathrm{C} / \mathrm{N}$ ratio and moisture content on the stability and maturity of compost. Bioresource Technology, Vol. 112, pp 171-178, 2002.

20. M. Koyama, N. Nagao, F. Syukri, A. Abd Rahim, M. S. Kamarudin, T. Toda, T. Mitsuhashi and K. Nakahashi. Effect of temperature on thermophilic composting of aquaculture sludge: $\mathrm{NH}_{3}$ recovery, nitrogen mass balance, and microbial community dynamics. Bioresource Technology, Vol. 265, pp 207-213, 2018.

21. B. Bech-friis, S. Smars, H. Jonssen, and H. Kirchmann. Gaseous emissions of carbon dioxide, ammonia and nitrous oxide from organic household waste in a compost reactor un-der different temperature regimes. Journal of Agricultural Engineering Research, Vol. 78, No. 4, pp 423-430, 2001.

22. Rakyat Malaysia hasil 37,890 tan sisa setiap hari (2019, Jun 16). Berita Harian.

23. S. Barrington, D. Choiniere, M. Trigui, and W. Knight. Compost convective airflow under passive aeration. Bioresource Technology, Vol. 86, No. 3, pp 259-266, 2003.

24. S. Darwaty. A study on the quality of compost derived from domestic organic wastes. Vol. 3, No. 1, pp 30-42, 2008. 